\title{
miR-133a function in the pathogenesis of dedifferentiated liposarcoma
}

\author{
Peter Y. Yu ${ }^{1,2}$, Gonzalo Lopez ${ }^{1,3}$, Danielle Braggio ${ }^{1,3}$, David Koller ${ }^{1,3}$, Kate Lynn J. Bill ${ }^{1,3}$, Bethany C. Prudner ${ }^{4}$, \\ Abbie Zewdu ${ }^{1,3}$, James L. Chen ${ }^{1,5}$, O. Hans Iwenofu ${ }^{1,6}$, Dina Lev ${ }^{7}$, Anne M. Strohecker ${ }^{1,3,8}$, Joelle M. Fenger ${ }^{9}$, \\ Raphael E. Pollock ${ }^{1,3^{*}}$ and Denis C. Guttridge $\mathrm{e}^{1,8^{*}}$
}

\begin{abstract}
Background: Sarcomas are malignant heterogeneous tumors of mesenchymal derivation. Dedifferentiated liposarcoma (DDLPS) is aggressive with recurrence in $80 \%$ and metastasis in $20 \%$ of patients. We previously found that miR-133a was significantly underexpressed in liposarcoma tissues. As this miRNA has recently been shown to be a tumor suppressor in many cancers, the objective of this study was to characterize the biological and molecular consequences of miR-133a underexpression in DDLPS.

Methods: Real-time PCR was used to evaluate expression levels of miR-133a in human DDLPS tissue, normal fat tissue, and human DDLPS cell lines. DDLPS cells were stably transduced with miR-133a vector to assess the effects in vitro on proliferation, cell cycle, cell death, migration, and metabolism. A Seahorse Bioanalyzer system was also used to assess metabolism in vivo by measuring glycolysis and oxidative phosphorylation (OXPHOS) in subcutaneous xenograft tumors from immunocompromised mice.

Results: miR-133a expression was significantly decreased in human DDLPS tissue and cell lines. Enforced expression of miR-133a decreased cell proliferation, impacted cell cycle progression kinetics, decreased glycolysis, and increased OXPHOS. There was no significant effect on cell death or migration. Using an in vivo xenograft mouse study, we showed that tumors with increased miR-133a expression had no difference in tumor growth compared to control, but did exhibit an increase in OXPHOS metabolic respiration.

Conclusions: Based on our collective findings, we propose that in DDPLS, loss of miR-133a induces a metabolic shift due to a reduction in oxidative metabolism favoring a Warburg effect in DDLPS tumors, but this regulation on metabolism was not sufficient to affect DDPLS.
\end{abstract}

Keywords: Sarcoma, Dedifferentiated liposarcoma, miR-133a, Metabolism

\section{Background}

Human liposarcoma is the most common adult softtissue sarcoma histologic subtype, and includes welldifferentiated/atypical lipomatous tumor (WDLPS) and dedifferentiated liposarcoma (DDLPS) [1]. WDLPS and DDLPS share similar 12q13-15 chromosomal amplification and supernumerary ring or giant chromosomes, but DDLPS exhibits more aggressive biological behavior with

\footnotetext{
*Correspondence: raphael.pollock@osumc.edu; denis.guttridge@osumc.

edu

${ }^{1}$ Arthur G. James Comprehensive Cancer Center, The Ohio State University, Columbus, $\mathrm{OH}$, USA

Full list of author information is available at the end of the article
}

frequent multiple recurrences and subsequent metastasis in spite of multimodality treatment approaches [2]. The identification of 12q13-15 chromosomal amplifications and MDM2/CDK4 overexpression in patients with DDLPS has provided insight into the genetic changes underlying the disease. The overall 5 -year survival rate is approximately $40-60 \%$. However, no significant improvement in survival times has been achieved in the past 35 years [3]. It is likely that until the molecular alterations that contribute to the development and progression of DDLPS are further identified and characterized, discovering novel targets for therapeutic intervention will remain challenging.

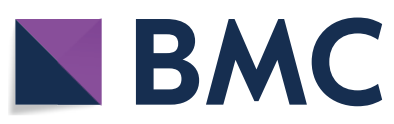

(c) The Author(s) 2018. This article is distributed under the terms of the Creative Commons Attribution 4.0 International License (http://creativecommons.org/licenses/by/4.0/), which permits unrestricted use, distribution, and reproduction in any medium, provided you give appropriate credit to the original author(s) and the source, provide a link to the Creative Commons license, and indicate if changes were made. The Creative Commons Public Domain Dedication waiver (http://creativecommons.org/ publicdomain/zero/1.0/) applies to the data made available in this article, unless otherwise stated. 
MiRNAs are evolutionarily conserved non-coding strands of RNA $\sim 22$ nucleotides in length that act as expression modulators of genes involved in fundamental cell processes, and their dysregulation have been implicated in multiple cancers [4, 5]. Many miRNAs have been identified to function as either tumor suppressors or oncogenes [6]. There are emerging data that seem to suggest that miRNAs may have a causal role in sarcomagenesis with potential therapeutic implications. Our understanding of miRNAs in liposarcoma is limited, but several profiling studies led to the identification of candidate tumor suppressor and oncogenic miRNAs. Other studies have proposed that miR-25, miR-26a, miR-92a, miR-145, and miR-155 function as potential therapeutic targets for DDLPS management [7-11]. These data imply miRNAs might act as drivers in the pathogenesis of DDLPS.

To this end, we recently characterized miRNA expression signatures associated with human liposarcoma tissue compared to paired subjacent normal tissue [12]. Unexpectedly, we found that several muscle-specific miRNAs (myomiRs), miR-1, -133a, and -206, were significantly underexpressed in liposarcoma compared to their subjacent normal tissues. These miRNAs play key roles in muscle differentiation and proliferation [13]. However, new findings indicate that myomiRs are involved in other processes such as adipocyte differentiation [14-16], chondrocyte differentiation [17], immunological responses [18], and mitochondrial function [19]. In addition, myomiRs have also been found to possess tumor suppressor function in over 14 human cancers [20], but have never been studied in a non-myogenic sarcoma. In this current study, we examined the role of miR-133a as a tumor suppressor in DDLPS.

\section{Methods}

\section{Cell culture and reagents}

Human LPS cell lines Lipo224B, Lipo246, Lipo863, and Lipo815 were established in our Sarcoma Research Laboratory as previously reported [21]. These cell lines were cultured in high glucose DMEM (Gibco, Carlsbad, CA, USA) with $10 \%$ fetal bovine serum (Atlanta Biologicals, Flowery Branch, GA, USA), supplemented with $0.1 \%$ Pen Strep (Gibco). Human white pre-adipocytes (HWP), derived from visceral adipose tissue, were obtained from PromoCell and cultured in mesenchymal stem cell medium, supplemented with the manufacturer's supplemental mix. Poietics Preadipocytes (PreAdip) derived from visceral fat from normal human donors were obtained from Lonza (Walkersville, MD, USA) and cultured in manufacturer's Preadipocyte Growth Media. Mature adipocytes were differentiated from preadipocytes by adding the manufacturer's supplemental mix to
Preadipocyte Growth Media according to manufacturer's suggestions. All cell lines were cultured in normal conditions at $37^{\circ} \mathrm{C}$ in a $5 \% \mathrm{CO}_{2}$ humidified chamber.

\section{Transfection and lentiviral infection}

For lentivirus production, lentiviral constructs were purchased from Systems Biosciences (Mountain View, CA, USA). Packaging of the lentiviral constructs was performed using the pPACKH1 Lentivector Packing KIT (Catalog No. LV500A-1) according to the manufacturer's recommendation. DDLPS cells were transduced with either an empty lentivirus (Catalog No. CD511B-1) or a pre-miR-133a (Catalog No. PMIRH133a1PA-1). FACSmediated cell sorting based on GFP expression was performed $72 \mathrm{~h}$ post-transduction, and miR-133a expression was evaluated by real-time PCR (Applied Biosystems, Foster City, CA, USA).

\section{RNA isolation and quantitative real-time PCR}

RNA was isolated using a GeneJET RNA Purification Kit (Thermo Fisher Scientific, Waltham, MA, USA) and real-time PCR was performed using the StepOne Plus Detection System (Applied Biosystems). RNA concentration and purity were measured using the NanoDrop 2000 (Thermo Fisher Scientific). Real-time PCR for mature miRNA expression was performed using Taqman miRNA assays (assay ID: 002246, miR-133a; 001973, U6 snRNA) (Applied Biosystems). 50 ng total RNA was converted to first-strand cDNA with miRNA-specific primers, followed by real-time PCR with Taqman probes. All samples were normalized to U6 snRNA. Real-time PCR was also performed for mRNA expression. $1 \mu \mathrm{g}$ of total RNA were used for synthesizing cDNA using iScript cDNA Synthesis Kit (Bio-Rad Laboratories, Hercules, CA, USA) in an iCycler (Bio-Rad Laboratories), and realtime PCR reactions were performed using SYBR Green (Roche, Indianapolis, IN, USA) with the following primer pairs: B2M: 5'-GAATTCACCCCCACTGAAAA-3' (forward), 5'-CCTCCATGATGCTGCTTACA-3' (reverse); CTGF: 5'-GAAGCTGACCTGGAAGAGAAC-3' (forward), 5'-CGTCGGTACATACTCCACAG-3' (reverse); MFN2: 5'-AGCTACACTGGCTCCAACTG-3' (forward), 5'-GAGCTCACTGTCCAACCAAC-3' (reverse). The $\triangle \triangle \mathrm{Ct}$ method was applied for all real-time PCR analysis.

\section{Proliferation and cell death assays}

DDLPS cells were seeded in 96-well plates (TPP) at a density of 3000-5000 cells per wells and time-lapse live cell imaging was conducted in $37{ }^{\circ} \mathrm{C}$ and $5 \% \mathrm{CO}_{2}$ conditions using the IncuCyte Zoom (Essen Bioscience, Ann Arbor, MI, USA) system, where 4 high-definition phasecontrast images were collected from each well every hour. IncuCyte Zoom 2015A software (Essen Bioscience) 
was used for analysis to apply a mask that determined the percent confluence based on the phase-contrast images. The percent confluence was normalized to the initial seeding confluence. For cell death assay, DDLPS cells were seeded as described above and stained with TOTO-3 (Molecular Probes, Eugene, OR, USA), a membrane impermanent nucleic acid probe. TOTO-3 fluorescence was measured by IncuCyte Zoom and the number of fluorescent cells was counted.

\section{Cell cycle assays}

DDLPS cells were synchronized by contact inhibition and serum deprivation. Cells were grown to confluence and subsequently cultured with $0.1 \%$ fetal bovine serum in DMEM for $36 \mathrm{~h}$. Cells were trypsinized and plated in 6 -well plates at $2 \times 10^{6}$ cells per well in normal $10 \%$ fetal bovine serum media. Cells were trypsinzed at time points of $0,15,24,33,36$, and $48 \mathrm{~h}$ and subsequently stained using a Propidium Iodide Flow Cytometry Kit (Abcam, Cambridge, UK) according to manufacturer's recommendation. DNA content analysis was performed by flow cytometry using Amnis FlowSight Imaging Flow Cytometer (End Millipore, Burlington, MA, USA) and IDEAS analysis software (End Millipore).

\section{Migration assays}

DDLPS cells were plated in 96-well ImageLock plates (Essen Bioscience) at density of $1.6 \times 10^{4}$ cells per well in the presence of mitomycin $\mathrm{C}(1 \mu \mathrm{g} / \mathrm{mL}$, received from Dr. Dario Palmieri) to inhibit proliferation. After $12 \mathrm{~h}$, Incucyte WoundMaker (Essen Bioscience) was used to make a uniform scratch in all 96 wells simultaneously. After rinsing with PBS, cells were placed in IncuCyte Zoom for time-lapse live cell imaging every hour for $24 \mathrm{~h}$. Incucyte Scratch Wound Cell Migration Software Module (Catalog No. 9600-0012) was used to apply a mask based on phase-contrast that analyzed the percentage of the wound infiltrated by the cells and determined the relative wound density (normalizing for initial density).

\section{Xenograft}

SCID hairless mice were purchased from Charles River Laboratories (Wilmington, MA, USA). Mice were housed under barrier conditions under IACUC protocol \#2014A00000085. 1-2 $\times 10^{6}$ cells were injected subcutaneously into the flank and tumor size was measured using calipers twice per week.

\section{Metabolism assays}

DDLPS cells were plated in XF24 cell culture microplates (Agilent, North Billerica, MA, USA) at densities of $2-4 \times 10^{4}$ cells per well. After overnight incubation, cells were washed using XF base media
(Agilent) supplemented with glucose $(10 \mathrm{mM}$, Sigma, St. Louis, MO, USA), pyruvate (2 $\mathrm{mM}$, Gibco), and L-glutamine ( $2 \mathrm{mM}$, Gibco). Cells were incubated for $1 \mathrm{~h}$ in a non- $\mathrm{CO}_{2}$ incubator. Cells were placed in Seahorse XFe24 Bioanalyzer (Agilent) for calibration and equilibration. MitoStress Test and GlycoStress Test were performed using glucose (10 mM, Sigma), oligomycin ( $1 \mu \mathrm{M}$, Sigma), FCCP $(2 \mu \mathrm{M}$, Sigma), rotenone $(2 \mu \mathrm{M}$, Sigma), and 2-deoxy-D-glucose (50 mM, Sigma).

For ex vivo metabolism studies, DDLPS tissues were obtained from subcutaneous xenograft tumor models as described above. After resection of DDLPS tumor, a biopsy punch (Integra LifeScience, Plainsboro, NJ, USA) was used to take a tissue core. The tissue core was embedded in 6\% Low Melting Point Agarose (Invitrogen, Carlsbad, CA, USA) and sliced at $200 \mu \mathrm{M}$ thickness using Vibratome 1000 Tissue Sectioning System (TPI, St. Louis, MO, USA). Tissue slices were placed in XF24 islet capture microplates with XF base media (Agilent) including $10 \mathrm{mM}$ glucose, $2 \mathrm{mM}$ pyruvate, and $2 \mathrm{mM}$ glutamine and incubated for $1 \mathrm{~h}$ in a non- $\mathrm{CO}_{2}$ incubator. Seahorse $\mathrm{XFe} 24$ Bioanalyzer was used for measuring oxygen consumption rate.

\section{Statistical analysis}

All quantitative data were presented as the mean \pm SEM. GraphPad Prism 6 (GraphPad Software, Inc., La Jolla, CA, USA) was used for statistical analysis including twotailed student's $t$ test, one-way ANOVA test, and two-way ANOVA test. $\mathrm{p}<0.05$ was considered to be statistically significant.

\section{Results \\ miR-133a is underexpressed in DDLPS cell lines and liposarcoma tissues}

Previous results showed that miR-1, miR-133a, and miR206 were under expressed in paired liposarcoma tumor tissues compared to their adjacent normal tissues [12]. Consistent with these results, we observed that miR-1, miR-133a, and miR-206 were also underexpressed in DDLPS cell lines 224B, 246, and 27 compared to control human preadipocyte cells (Fig. 1a-c). Interestingly, miR133a, plays a role in adipocyte differentiation [14, 15], and amongst the other myomiRs was strongly downregulated in DDLPS cell lines compared to control cells. To expand our analysis, we focused our study on the expression of miR-133a in a larger cohort of DDLPS cells lines $(\mathrm{n}=10)$. Similar to our original finding, miR-133a was significantly underexpressed in DDLPS cells compared to control adipose (Fig. 1d). Furthermore, miR-133a was significantly under expressed in unpaired human liposarcoma tumor tissues compared to normal fat (Fig. 1e). 


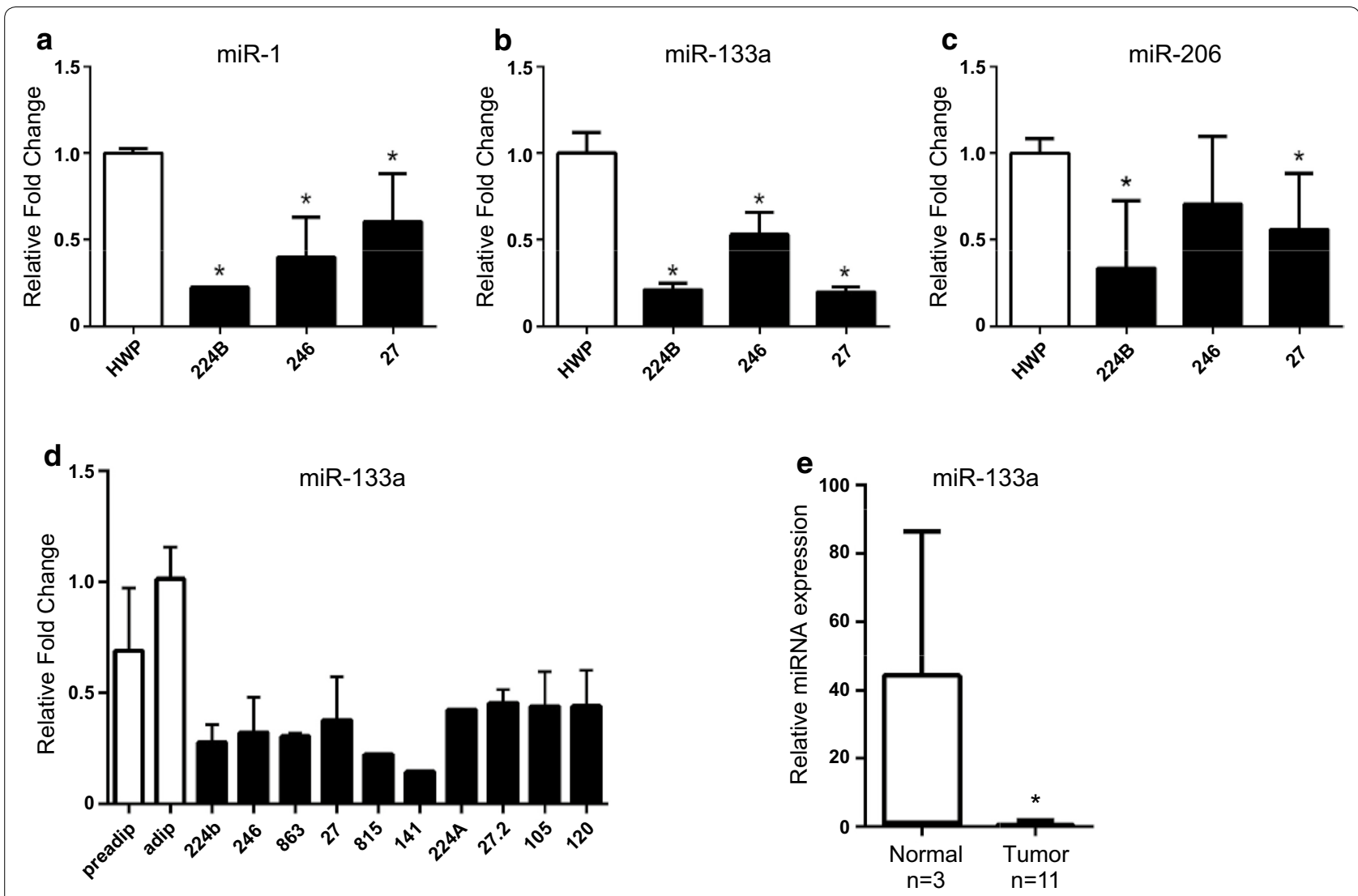

Fig. 1 miR-133a is under expressed in DDLPS cell lines and liposarcoma tissues. a-c Expression levels of miR-1 (a), miR-133a (b), and miR-206 (c) were measured using real-time RT-PCR in human white preadipocyte cell line (HWP) and DDLPS cell lines (224B, 246, 27). Fold changes were calculated with the $2^{-\triangle \Delta C T}$ method, using U6 snRNA as a housekeeping gene. Data are plotted as mean \pm SEM for each miRNA performed in triplicate. ${ }^{*} p<0.05$. $\mathbf{d}$ Real-time RT-PCR analyzed miR-133a expression level in a DDLPS cell line panel, along with preadipocytes (preadip) and adipocytes (adip) used as normal controls. Fold changes were calculated with the $2^{-\triangle \Delta C T}$ method, using U6 snRNA as a housekeeping gene. Data are plotted as mean \pm SEM. e Human tissues were analyzed by real-time RT-PCR for miR-133a expression. Tumor tissue included 11 liposarcomas and normal tissue included three normal adjacent tissues. Data are plotted as box and whisker plot. ${ }^{*} \mathrm{p}<0.05$

Such data suggest that miR-133a might function as a tumor suppressor in human liposarcoma.

\section{miR-133a overexpression is associated with decreased cell growth of DDLPS cells in vitro}

To test the relevance of miR-133a expression in DDLPS, we stably expressed miR-133a using lentiviral pre-miR133a transduction in human DDLPS cells (Fig. 2a). To validate the relevance of miR-133a overexpression, we probed for a previously identified target of this miRNA called connective tissue growth factor (CTGF) [22]. As anticipated, miR-133a overexpression reduced the levels of CTGF in DDLPS cells compared to control vector cells (Fig. 2b). Compared to empty vector control, cell growth was significantly reduced $(\mathrm{p}<0.05)$ in miR-133a-overexpressing DDLPS cell lines (Fig. 2c). We subsequently inquired whether changes in cell growth were mediated by a defect in the cell cycle. Using the same DDLPS cell line stably transduced with miR-133a or control vector, we performed propidium iodide staining to study the kinetics of cell progression via the cell cycle. Results showed that DDLPS cells expressing miR-133a were delayed in entering $\mathrm{S}$ phase at 33 and $36 \mathrm{~h}$ (Fig. 2d).

We next investigated whether expression of miR-133a impacted cell death. By TOTO-3 staining for nucleic acid, we were unable to observe a difference in cell death between vector control and miR-133a expressing DDLPS cells (data not shown). We also investigated the potential role of miR-133a in promoting DDLPS cell migration. However, results from a wound scratch assay did not show significant differences between vector and miR133a expressing DDLPS cells (Additional file 1: Figure $\mathrm{S} 1 \mathrm{a}, \mathrm{b})$. Together, these results suggested that miR-133a is capable of impairing DDLPS cell growth, but this regulation correlated only modestly with the cell cycle, but not with cell death or cell migration. 


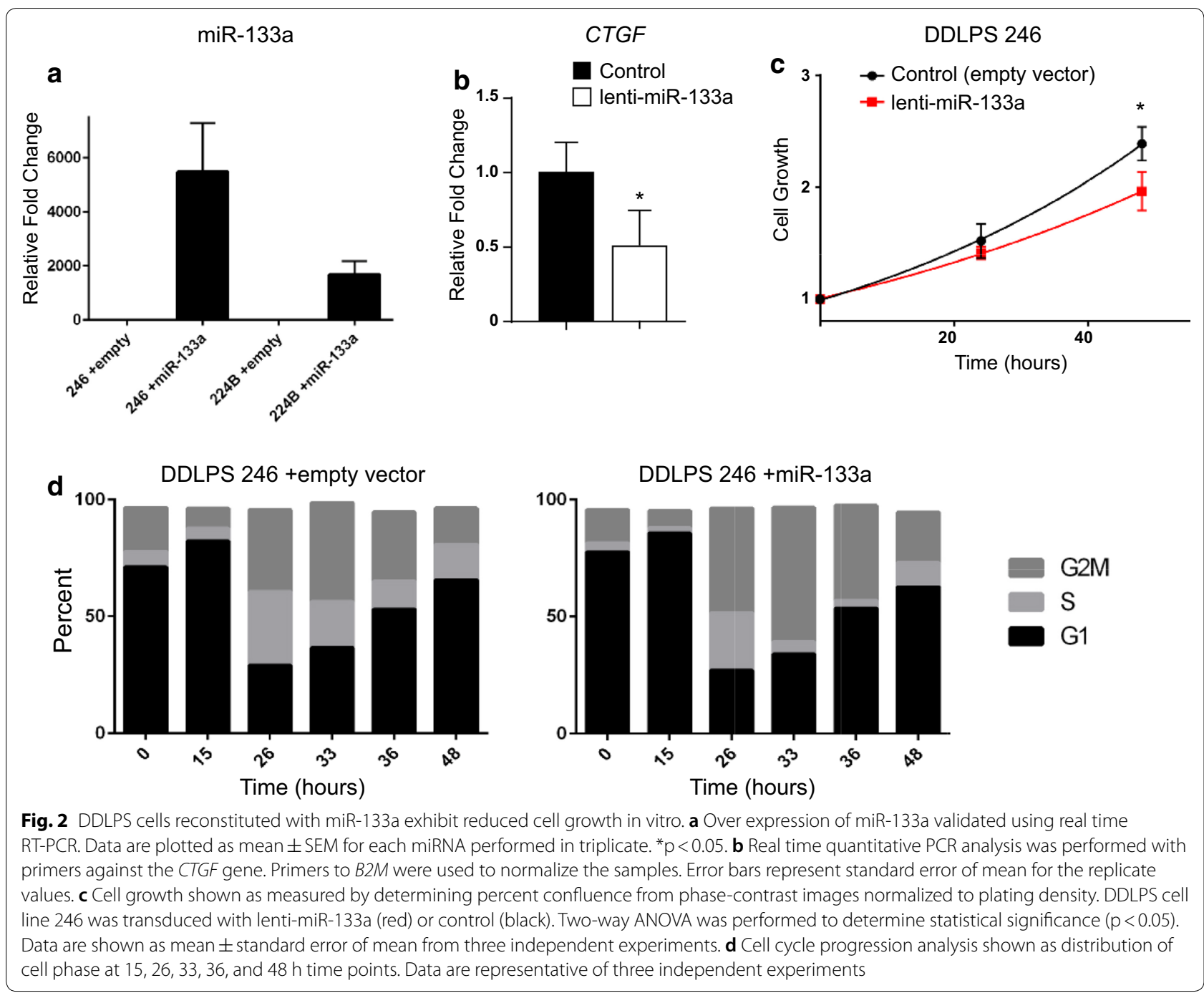

DDLPS cells re-expressed with miR-133a showed increased mitochondrial function and decreased glycolytic capacity Having observed a modest effect on proliferation, but no effect on cell death or migration, we investigated whether miR-133 expression in DDLPS affected the metabolic profile of these cells. Using the Seahorse bioanalyzer, Mito Stress tests revealed that reconstitution of miR133a in DDLPS cells led to higher maximal respiration from an increased oxidative phosphorylation (OXPHOS) capacity (Fig. 3a, b). Correspondingly, a Glyco Stress test showed that expression of miR-133a decreased glycolysis in DDLPS, compared to vector control cells (Fig. 3c, d). Since high mitochondrial respiratory capacity is associated with mitochondrial fusion [23], we examined the expression of mitofusin 2 (MFN2), a gene which is essential for mitochondrial fusion and also regulates glucose homeostasis [24]. We found increased expression of MFN2 associated with reconstitution of miR-133a in
DDLPS cells (Fig. 3e). Together, these results indicate that re-constitution of miR-133a in DDLPS cells promotes a reduction in glycolysis and an increase in OXPHOS.

Reconstitution of miR-133a does not reduce DDLPS tumor growth but promotes a metabolic shift in vivo

To examine the in vivo relevance of our findings, we subcutaneously injected human DDLPS cells stably expressing miR-133a or a scrambled miRNA control in SCID mice $[10,25,26]$. Reconstitution of miR-133a in DDLPS cells did not affect tumor growth (Fig. 4a) nor was there a difference in Ki67 by immunohistochemistry staining. This suggested that miR-133a does not impact DDLPS cellular proliferation in vivo (Fig. 4b). In addition, consistent with in vitro findings, miR-133a showed no difference in cleaved caspase 3 (CC3) by immunohistochemistry staining versus control DDLPS cells (Fig. 4b), 

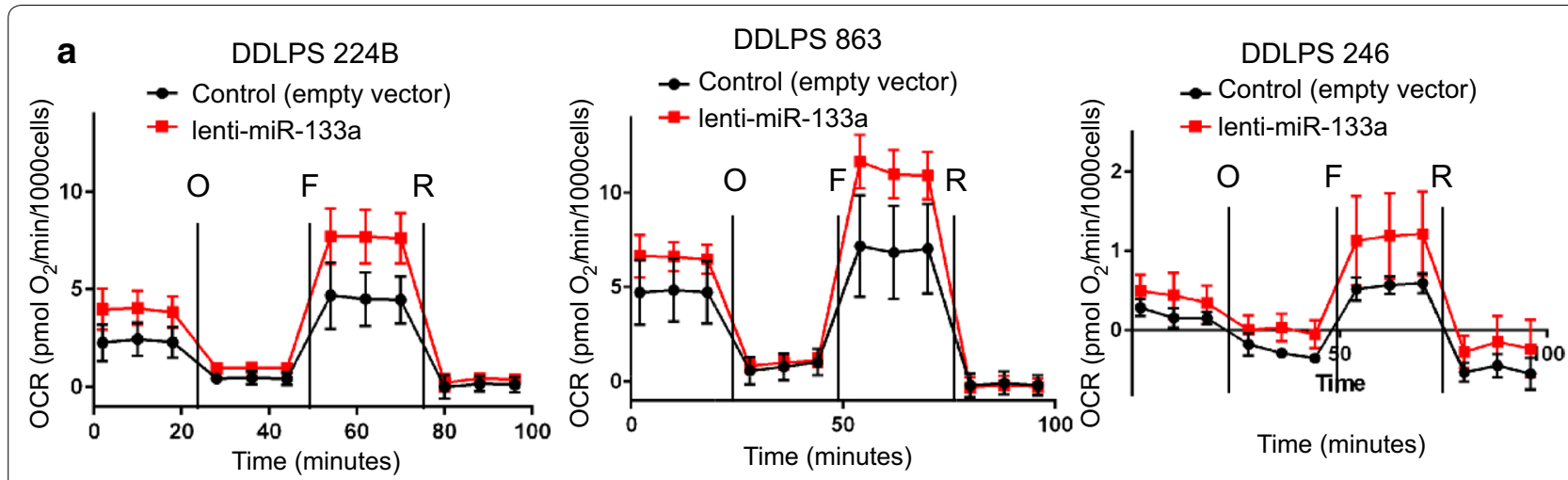

\section{b $\square$ Spare respiratory capacity $\square$ Basal respiration}
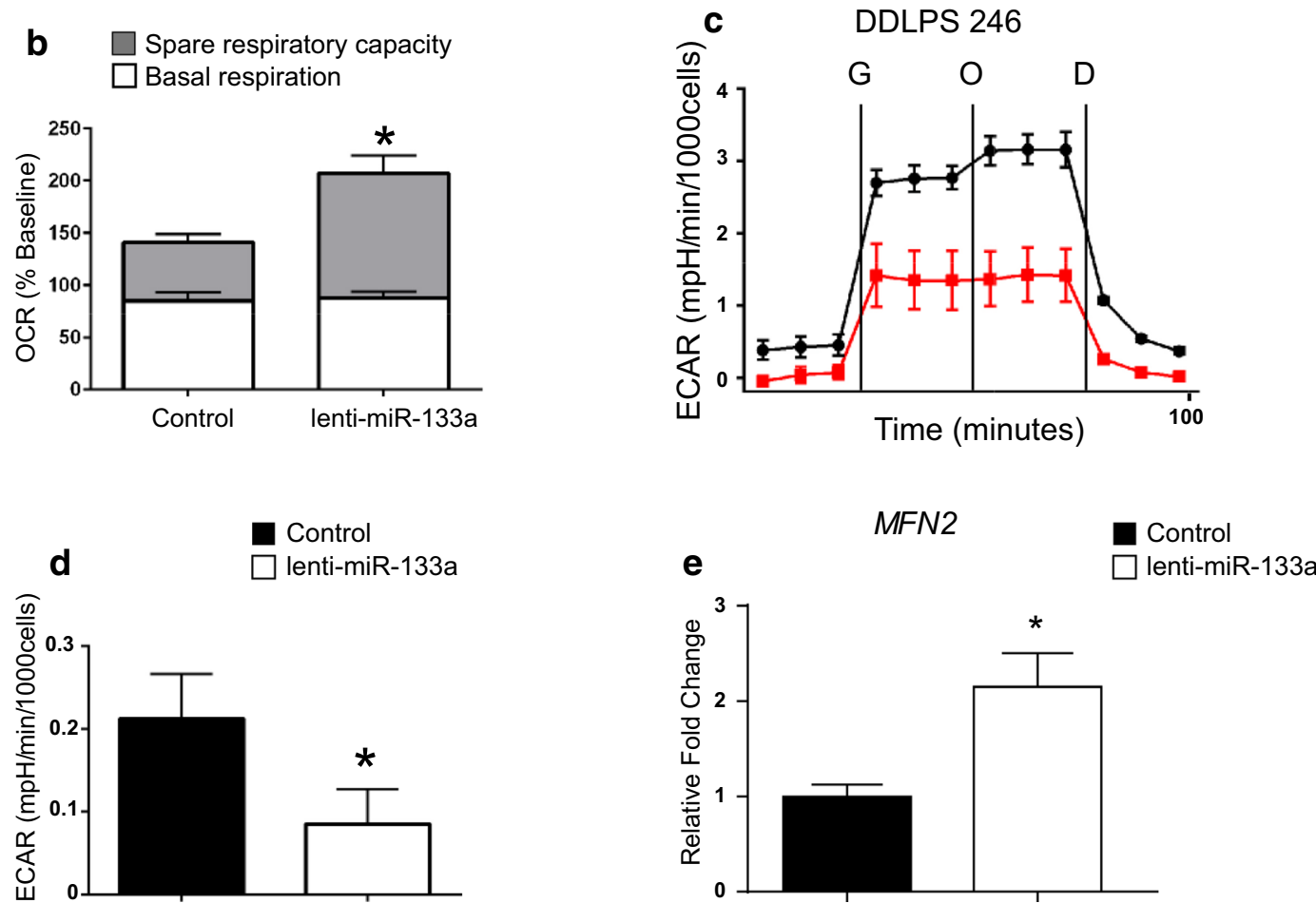

Fig. 3 DDLPS cells reconstituted with miR-133a show shifted mitochondrial function linked to energy balance. a Mitostress Test was performed in DDLPS cell lines 224B, 863, and 246. b OCR values shown after injection of FCCP relative to baseline OCR measurement $(n=3)$. ${ }^{*} p<0.05$. $\mathbf{c}$ Glycostress Test was performed in DDLPS cell line 246. $\mathbf{d}$ Basal glycolysis was measured by baseline ECAR subtracted by non-glucose-derived ECAR (ECAR values after injection of 2-deoxyglucose). e Real time quantitative PCR analysis was performed with primers against the MFN2 gene. Primers to B2M were used to normalize the samples. Error bars represent standard error of mean for the replicate values. D 2-deoxy-D-glucose, ECAR extracellular acidification rate, $F$ carbonyl cyanide-4-(trifluoromethoxy)phenylhydrazone), G glucose, OCR oxygen consumption rate, $O$ oligomycin, $R$ rotenone

which confirmed that loss of miR-133a does not mediate tumor cell growth or survival.

To determine whether miR-133a has an impact on tumor metabolism as we had observed in culture conditions, we profiled dissected DDLPS tumors from mice at endpoint and analyzed fresh, unfixed, tumor sections directly on the Seahorse analyzer.
Significantly, reconstitution of miR-133a increased the baseline oxygen consumption rate in DDLPS tumors (Fig. 4c), directly reflecting an increase in OXPHOS. These data support the concept that miR133a functions as a regulator of oxidative metabolism in adipocyte cells and loss of this miR leads to a shift in metabolism favoring a Warburg effect in DDLPS tumors. 

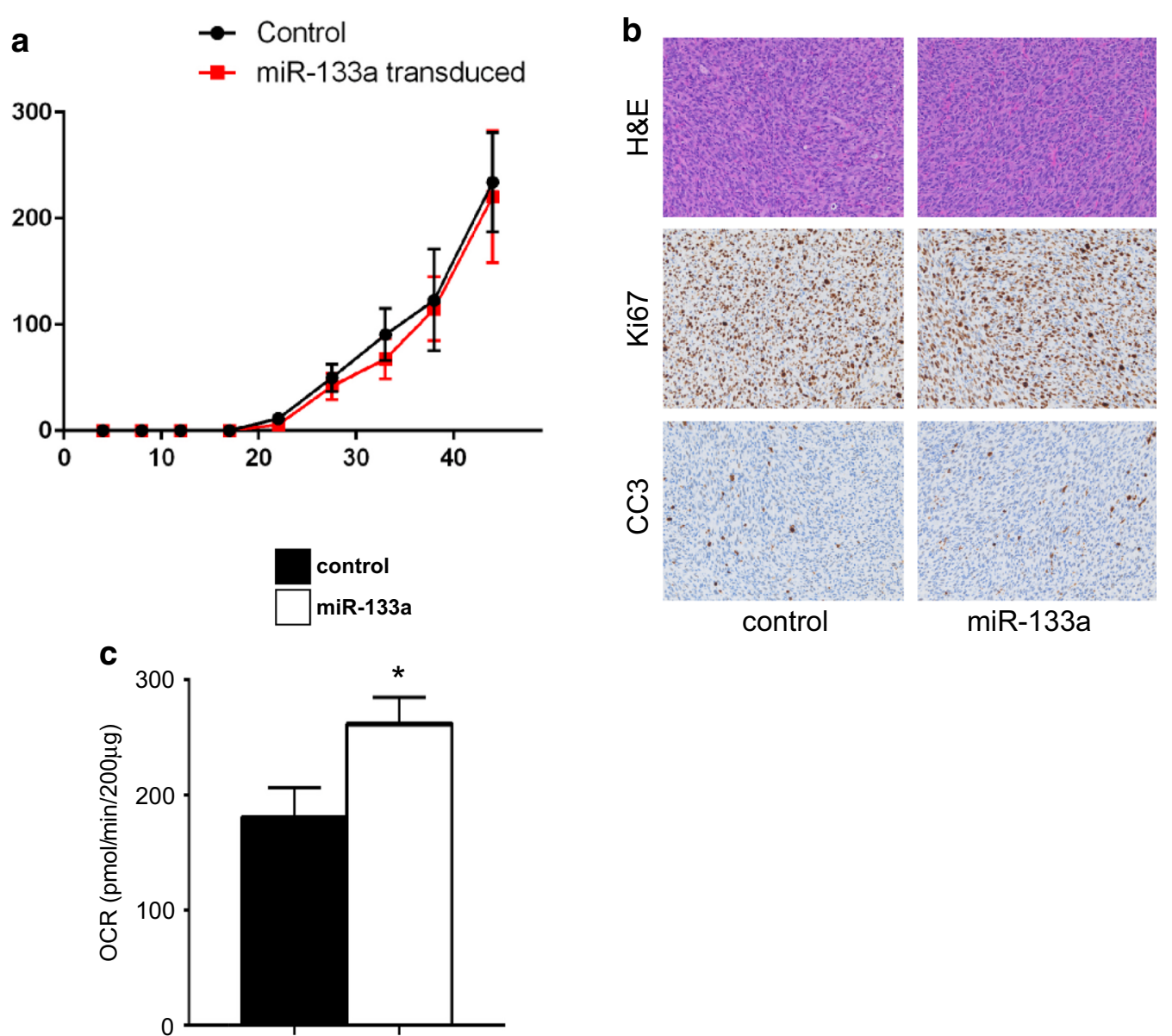

Fig. 4 Re-expression of miR-133a impacts DDLPS tumor cell metabolism. a DDLPS 246 cells were subcutaneously injected into SCID mice $(n=6$ per condition). Tumor area was measured twice per week using calipers. b H\&E staining along with immunohistochemistry staining for Ki67 and cleaved caspase 3 (CC3). c OCR measurements of ex vivo tumor tissues shown normalized to dried tissue mass

\section{Discussion}

This study was performed to determine the role of miR133a in DDLPS. Our findings support the contention that miR-133a is decreased in DDLPS compared to normal cells. By stably reconstituting miR-133a in human DDLPS cells, we observed a decrease in proliferation and a shift in metabolism from a glycolytic to an OXPHOS phenotype. When DDLPS cells expressing miR-133a were injected in a murine in vivo xenograft model, tumor growth was unchanged, but a shift towards oxidative metabolism was retained. This implied that in DDLPS, loss of miR-133a contributes to the shift in tumor cells utilizing glycolysis as a main energy source. The tumor suppressor role of miR-133a and its family (including miR-1, miR-133b, and miR-206), were originally described in the muscle relevant cancer, rhabdomyosarcoma, due to their multiple roles in promoting skeletal muscle differentiation. Following their discovery in rhabdomyosarcoma, other tumor types were found to be associated with loss of these miRs [20]. With miR-133a, this included bladder, breast, colorectal, and gastric cancers [26-31]. In breast cancer, loss of miR-133a promotes cell cycle and cell proliferation due to the increase in the epithelial growth factor receptor (EGFR), identified as a miR-133a target [27]. In colorectal cancer, miR-133a represses tumor growth by targeting LASP1 [29] and RFFL [30], which function by inducing cell proliferation and inhibiting the p53/p21 signaling pathway, respectively.

In contrast, in DDLPS, we did not find miR-133a to be strongly involved in cell cycle regulation, nor were any migration or cell survival effects observed. Instead miR-133a seemed to play a more vital role in regulating metabolism. This is consistent with miR-133a function to promote glucose transport in cardiac cells by targeting KLF15 [32], which acts as a negative regulator of the glucose transporter, GLUT4, and to induce the differentiation of brown fat by targeting Prdm16 in skeletal muscle progenitor cells [16]. 
Metabolic reprogramming has emerged as one of the key hallmarks of cancer [30, 31]. A distinctive feature of tumor cells compared to normal cells is their ability to thrive in a variety of microenvironments including hypoxic and nutrient-depleted backgrounds. The most fundamental metabolic alteration is that cancer cells exhibit aerobic glycolysis, a process in which cells increase glucose consumption and undergo glycolysis even in the presence of oxygen [33, 34]. Although the ATP yield per glucose molecule is much lower through glycolysis than through aerobic respiration, cancer cells can utilize this pathway to expediently acquire energy to support rapid cellular proliferation [35]. This glycolytic phenotype was proposed by Otto Warburg to be associated with weak mitochondrial oxidative phosphorylation [36], but this view has been challenged by investigations showing that mitochondrial oxidative phosphorylation is intact in most cancers [37]. The increased dependence of cancer cells on aerobic glycolysis led to development of therapeutic strategies that pharmacologically inhibit glycolysis [33]. However, the potential therapeutic benefits will likely be context- and tumor type-dependent based upon whether the cancer cells are dependent on glycolysis or mitochondrial oxidative phosphorylation $[38,39]$.

An interesting result in our study was that miR-133a impacted metabolism of tumor cells in vivo. To the best of our knowledge, our findings are the first to show results from live tumor tissue utilizing the Seahorse Bioanalyzer. We adopted this method from a previous study where we successfully measured the oxygen consumption rate of intact skeletal muscle [40]. We found that overexpressing miR-133a in DDLPS cells increased OXPHOS both in vitro and ex vivo. However, this shift in metabolism was not sufficient to alter tumor growth. It is possible that the regulation on metabolism by miR-133a might have stronger implications earlier in the pathogenesis of DDLPS. Support for this notion comes from a genetically engineered mouse model of DDLPS, where Notch receptor activation in adipocytes induced DDLPS [41]. In this DDLPS model, Notch activation suppressed lipid metabolism pathways, and administration of the synthetic PPAR $\gamma$ ligand rosiglitazone reversed the metabolic alteration and dedifferentiation in DDLPS tumors. It is therefore possible that increased expression of miR-133a could comparably alter lipid metabolism pathways and thereby prevent early progression of DDLPS.

\section{Conclusion}

In this study, we demonstrated that overexpression of miR-133a in DDLPS induces a shift in metabolism from a glycolytic to an oxidative phenotype. We have further shown in an in vivo xenograft model that a shift to oxidative metabolism is retained. These findings suggest the possibility that miR-133a could function as a regulator of oxidative metabolism in DDLPS tumors.

\section{Additional file}

Additional file 1: Figure S1. DDLPS cells reconstituted with miR-133a do not show differences in migration. a Scratch wound assay was performed in DDLPS cell line 246 transduced with lenti-miR-133a (top) or control (bottom). The initial scratch wound mask was created immediately after wound creation and is shown in blue. Phase contrast-images were taken as cells (yellow) migrate in to the wound region over time. $\mathbf{b}$ Relative wound density was calculated by Incucyte Scratch Wound Cell Migration Software.

\section{Abbreviations}

DDLPS: dedifferentiated liposarcoma; EGFR: epidermal growth factor receptor; HWP: human white preadipocyte; OXPHOS: oxidative phosphorylation; WDLPS: well-differentiated liposarcoma.

\section{Authors' contributions}

PY, RP, and DG conceived and designed the experiments. PY performed the experiments and $G L$ contributed to in vivo experiments. DB, DK, KB, BP, and JF provided technical assistance. PY, HI, DL, and AS analyzed the data. JC contributed analysis tools. PY, RP, and DG wrote the paper. All authors read and approved the final manuscript.

\section{Author details}

${ }^{1}$ Arthur G. James Comprehensive Cancer Center, The Ohio State University, Columbus, OH, USA. ${ }^{2}$ College of Medicine, The Ohio State University, Columbus, OH, USA. ${ }^{3}$ Division of Surgical Oncology, Department of Surgery, The Ohio State University, Columbus, OH, USA. ${ }^{4}$ Division of Medical Oncology, Department of Internal Medicine, The Ohio State University, Columbus, $\mathrm{OH}$, USA. ${ }^{5}$ Biomedical Informatics, Internal Medicine in the Division of Medical Oncology, The Ohio State University, Columbus, OH, USA. ${ }^{6}$ Department of Pathology \& Laboratory Services, The Ohio State University, Columbus, $\mathrm{OH}$, USA. ${ }^{7}$ Department of Surgery, Sheba Medical Center, Tel Aviv, Israel. ${ }^{8}$ Department of Cancer Biology and Genetics, The Ohio State University, Columbus, $\mathrm{OH}$, USA. ${ }^{9}$ Department of Veterinary Clinical Sciences, College of Veterinary Medicine, The Ohio State University, Columbus, OH, USA.

\section{Acknowledgements}

We would like to thank all the members of the Guttridge laboratory and Sarcoma research laboratory for their engaging discussions throughout the course of this study.

\section{Competing interests}

The authors declare that they have no competing interests.

\section{Availability of data and materials}

All data used and/or analyzed during the current study are available from the corresponding author on reasonable request.

\section{Consent for publication}

Not applicable.

\section{Ethics approval and consent to participate}

All procedures were conducted under The Ohio State University's Institutional Animal Care and Use Committee (IACUC) approval (Number 2014A00000085) and in accordance with The Ohio State University's Animal Welfare Assurance (Number A3261-01). Tissue samples from patients were collected from OSU James Cancer Medical Center (Columbus, $\mathrm{OH}$ ) following written informed consent whose protocols have been approved by The Ohio State University Wexner Medical Center Institutional Review Board. 


\section{Funding}

This work was supported in part by NIH Grants, R01 CA143082 (DCG), U54 CA168512 (REP), P01 CA163995 (DCG), by an OSU College of Medicine Bennett research scholarship (PYY), by the Ohio State University Cancer Center Pelotonia Fellowship program (PYY), and by an Alpha Omega Alpha Carolyn L. Kuckein Student Research Fellowship (PYY). The content is solely the responsibility of the authors and does not necessarily represent the official views of the $\mathrm{NIH}$.

\section{Publisher's Note}

Springer Nature remains neutral with regard to jurisdictional claims in published maps and institutional affiliations.

Received: 21 January 2018 Accepted: 12 June 2018

Published online: 26 June 2018

\section{References}

1. Coindre JM, Pedeutour F, Aurias A. Well-differentiated and dedifferentiated liposarcomas. Virchows Arch. 2010:456:167-79.

2. Tseng WW, Somaiah N, Lazar AJ, Lev DC, Pollock RE. Novel systemic therapies in advanced liposarcoma: a review of recent clinical trial results. Cancers. 2013;5:529-49.

3. Pedeutour F, Maire G, Pierron A, Thomas DM, Garsed DW, Bianchini L, Duranton-Tanneur V, Cortes-Maurel A, Italiano A, Squire JA, Coindre JM. A newly characterized human well-differentiated liposarcoma cell line contains amplifications of the 12q12-21 and 10p11-14 regions. Virchows Arch. 2012;461:67-78.

4. Jansson MD, Lund AH. MicroRNA and cancer. Mol Oncol. 2012;6:590-610.

5. Hayes J, Thygesen H, Tumilson C, Droop A, Boissinot M, Hughes TA, Westhead D, Alder JE, Shaw L, Short SC, Lawler SE. Prediction of clinical outcome in glioblastoma using a biologically relevant nine-microRNA signature. Mol Oncol. 2015;9:704-14.

6. Kent OA, Mendell JT. A small piece in the cancer puzzle: microRNAs as tumor suppressors and oncogenes. Oncogene. 2006;25:6188-96.

7. Bianchini L, Saada E, Gjernes E, Marty M, Haudebourg J, BirtwislePeyrottes I, Keslair F, Chignon-Sicard B, Chamorey E, Pedeutour F. Let-7 microRNA and HMGA2 levels of expression are not inversely linked in adipocytic tumors: analysis of 56 lipomas and liposarcomas with molecular cytogenetic data. Genes Chromosomes Cancer. 2011:50:442-55.

8. Lee DH, Amanat S, Goff C, Weiss LM, Said JW, Doan NB, Sato-Otsubo A, Ogawa S, Forscher C, Koeffler HP. Overexpression of miR-26a-2 in human liposarcoma is correlated with poor patient survival. Oncogenesis. 2013;2:e47.

9. Gits CM, van Kuijk PF, Jonkers MB, Boersma AW, Smid M, van ljcken WF, Coindre JM, Chibon F, Verhoef C, Mathijssen RH, den Bakker MA, Verweij J, Sleijfer S, Wiemer EA. MicroRNA expression profiles distinguish liposarcoma subtypes and implicate miR-145 and miR-451 as tumor suppressors. Int J Cancer. 2014;135:348-61.

10. Zhang P, Bill K, Liu J, Young E, Peng T, Bolshakov S, Hoffman A, Song Y, Demicco EG, Terrada DL, Creighton CJ, Anderson ML, Lazar AJ, Calin GG, Pollock RE, Lev D. miR-155 is a liposarcoma oncogene that targets casein kinase-1alpha and enhances beta-catenin signaling. Cancer Res. 2012;72:1751-62.

11. Casadei L, Calore F, Creighton CJ, Guescini M, Batte K, Iwenofu OH, Zewdu A, Braggio DA, Bill KL, Fadda P, Lovat F, Lopez G, Gasparini P, Chen JL, Kladney RD, Leone G, Lev D, Croce CM, Pollock RE. Exosomederived miR-25-3p and miR-92a-3p stimulate liposarcoma progression. Cancer Res. 2017;77:3846-56.

12. Yu PY, Balkhi MY, Ladner KJ, Alder H, Yu L, Mo X, Kraybill WG, Guttridge $\mathrm{DC}$, Iwenofu $\mathrm{OH}$. A selective screening platform reveals unique global expression patterns of microRNAs in a cohort of human soft-tissue sarcomas. Lab Invest. 2016;96:481-91.

13. Chen JF, Mandel EM, Thomson JM, Wu Q, Callis TE, Hammond SM, ConIon FL, Wang DZ. The role of microRNA-1 and microRNA-133 in skeletal muscle proliferation and differentiation. Nat Genet. 2006:38:228-33.
14. Trajkovski M, Ahmed K, Esau CC, Stoffel M. MyomiR-133 regulates brown fat differentiation through Prdm16. Nat Cell Biol. 2012;14:1330-5

15. Liu W, Bi P, Shan T, Yang X, Yin H, Wang YX, Liu N, Rudnicki MA, Kuang S. miR-133a regulates adipocyte browning in vivo. PLoS Genet. 2013;9:e1003626

16. Yin $H$, Pasut $A$, Soleimani VD, Bentzinger CF, Antoun G, Thorn S, Seale P, Fernando P, van ljcken W, Grosveld F, Dekemp RA, Boushel R, Harpe ME, Rudnicki MA. MicroRNA-133 controls brown adipose determination in skeletal muscle satellite cells by targeting Prdm16. Cell Metab. 2013;17:210-24

17. Li P, Wei X, Guan Y, Chen Q, Zhao T, Sun C, Wei L. MicroRNA-1 regulates chondrocyte phenotype by repressing histone deacetylase 4 during growth plate development. FASEB J. 2014;28:3930-41.

18. Stumpfova Z, Hezova R, Meli AC, Slaby O, Michalek J. MicroRnA profiling of activated and tolerogenic human dendritic cells. Mediators Inflamm. 2014;2014:259689.

19. Zhang X, Zuo X, Yang B, Li Z, Xue Y, Zhou Y, Huang J, Zhao X, Zhou J, Yan Y, Zhang H, Guo P, Sun H, Guo L, Zhang Y, Fu XD. MicroRNA directly enhances mitochondrial translation during muscle differentiation. Cell. 2014;158:607-19.

20. Mitchelson KR, Qin WY. Roles of the canonical myomiRs miR-1, -133 and -206 in cell development and disease. World J Biol Chem. 2015;6:162-208.

21. Peng T, Zhang P, Liu J, Nguyen T, Bolshakov S, Belousov R, Young ED, Wang X, Brewer K, Terrada LL, Oliveira AM, Lazar AJ, Lev D. An experimental model for the study of well differentiated and dedifferentiated liposarcoma; deregulation of targetable tyrosine kinase receptors. Lab Invest. 2011:91(3):392-403

22. Duisters RF, Tijsen AJ, Schroen B, Leenders JJ, Lentink $V$, van der Made I, Herias V, van Leeuwen RE, Schellings MW, Barenbrug P, Maessen JG, Heymans S, Pinto YM, Creemers EE. miR-133 and miR-30 regulate connective tissue growth factor: implications for a role of microRNAs in myocardial matrix remodeling. Circ Res. 2009;104:170-8.

23. Willems PH, Rossignol R, Dieteren CE, Murphy MP, Koopman WJ. Redox homeostasis and mitochondrial dynamics. Cell Metab. 2015;22:207-18.

24. Sebastian D, Hernandez-Alvarez MI, Segales J, Sorianello E, Munoz JP, Sala D, Waget A, Liesa M, Paz JC, Gopalacharyulu P, Oresic M, Pich S, Burcelin R, Palacin M, Zorzano A. Mitofusin 2 (Mfn2) links mitochondrial and endoplasmic reticulum function with insulin signaling and is essential for normal glucose homeostasis. Proc Natl Acad Sci USA. 2012;109:5523-8.

25. Bill KL, Garnett J, Ma X, May CD, Bolshakov S, Lazar AJ, Lev DC, Pollock RE. The hepatocyte growth factor receptor as a potential therapeutic target for dedifferentiated liposarcoma. Lab Invest. 2015;95:951-61.

26. Bill KL, Garnett J, Meaux I, Ma X, Creighton CJ, Bolshakov S, Barriere C, Debussche L, Lazar AJ, Prudner BC, Casadei L, Braggio D, Lopez G, Zewdu A, Bid H, Lev D, Pollock RE. SAR405838: a novel and potent inhibitor of the MDM2:p53 axis for the treatment of dedifferentiated liposarcoma. Clin Cancer Res. 2016;22:1150-60.

27. Cui W, Zhang S, Shan C, Zhou L, Zhou Z. microRNA-133a regulates the cell cycle and proliferation of breast cancer cells by targeting epidermal growth factor receptor through the EGFR/Akt signaling pathway. FEBS J. 2013;280:3962-74.

28. Chiyomaru T, Enokida H, Tatarano S, Kawahara K, Uchida Y, Nishiyama K, Fujimura L, Kikkawa N, Seki N, Nakagawa M. miR-145 and miR-133a function as tumour suppressors and directly regulate FSCN1 expression in bladder cancer. Br J Cancer. 2010;102:883-91.

29. Wang H, An H, Wang B, Liao Q, Li W, Jin X, Cui S, Zhang Y, Ding Y, Zhao L. miR-133a represses tumour growth and metastasis in colorectal cancer by targeting LIM and SH3 protein 1 and inhibiting the MAPK pathway. Eur J Cancer. 2013:49:3924-35.

30. Dong Y, Zhao J, Wu CW, Zhang L, Liu X, Kang W, Leung WW, Zhang N, Chan FK, Sung JJ, Ng SS, Yu J. Tumor suppressor functions of miR-133a in colorectal cancer. Mol Cancer Res. 2013;11:1051-60.

31. Cheng Z, Liu F, Wang G, Li Y, Zhang H, Li F. miR-133 is a key negative regulator of CDC42-PAK pathway in gastric cancer. Cell Signal. 2014;26:2667-73.

32. Horie T, Ono K, Nishi H, Iwanaga Y, Nagao K, Kinoshita M, Kuwabara Y, Takanabe R, Hasegawa K, Kita T, Kimura T. MicroRNA-133 regulates the expression of GLUT4 by targeting KLF15 and is involved in 
metabolic control in cardiac myocytes. Biochem Biophys Res Commun. 2009;389:315-20.

33. Pelicano H, Xu RH, Du M, Feng L, Sasaki R, Carew JS, Hu Y, Ramdas L, Hu L, Keating MJ, Zhang W, Plunkett W, Huang P. Mitochondrial respiration defects in cancer cells cause activation of Akt survival pathway through a redox-mediated mechanism. J Cell Biol. 2006;175:913-23.

34. Parks SK, Chiche J, Pouyssegur J. Disrupting proton dynamics and energy metabolism for cancer therapy. Nat Rev Cancer. 2013;13:611-23.

35. Vander Heiden MG, Cantley LC, Thompson CB. Understanding the Warburg effect: the metabolic requirements of cell proliferation. Science. 2009;324:1029-33.

36. Warburg O. On the origin of cancer cells. Science. 1956;123:309-14.

37. Zheng J. Energy metabolism of cancer: glycolysis versus oxidative phosphorylation (Review). Oncol Lett. 2012;4:1151-7.
38. Zhang Y, Yang JM. Altered energy metabolism in cancer: a unique opportunity for therapeutic intervention. Cancer Biol Ther. 2013;14:81-9.

39. Moreno-Sanchez R, Rodriguez-Enriquez S, Marin-Hernandez A, Saavedra E. Energy metabolism in tumor cells. FEBS J. 2007;274:1393-418.

40. Shintaku J, Guttridge DC. Analysis of aerobic respiration in intact skeletal muscle tissue by microplate-based respirometry. Methods Mol Biol. 2016;1460:337-43.

41. Bi P, Yue F, Karki A, Castro B, Wirbisky SE, Wang C, Durkes A, Elzey BD, Andrisani OM, Bidwell CA, Freeman JL, Konieczny SF, Kuang S. Notch activation drives adipocyte dedifferentiation and tumorigenic transformation in mice. J Exp Med. 2016;213:2019-37.
Ready to submit your research? Choose BMC and benefit from:

- fast, convenient online submission

- thorough peer review by experienced researchers in your field

- rapid publication on acceptance

- support for research data, including large and complex data types

- gold Open Access which fosters wider collaboration and increased citations

- maximum visibility for your research: over $100 \mathrm{M}$ website views per year

At BMC, research is always in progress.

Learn more biomedcentral.com/submissions 